\title{
QUALIDADE DE SEMENTES DE Phaseolus vulgaris L. NO CONTEXTO DA SUSTENTABILIDADE
}

Yuri de Carli ${ }^{1}$, Cleiltan Novais da Silva ${ }^{2}$, Francielli Gasparotto ${ }^{3}$, Thais de Oliveira lácono Ramari ${ }^{4}$, Edneia Aparecida de Souza Paccola ${ }^{5}$

${ }^{1}$ Graduando do curso de Engenharia Agronômica do Centro Universitário de Maringá, Unicesumar - Maringá.

${ }^{2}$ Pós-doutoranda do programa de Pós-graduação em Tecnologias Limpas do Centro Universitário de Maringá, Unicesumar - Maringá

${ }^{3}$ Prof $^{\mathrm{a}}$. Dr ${ }^{\mathrm{a}}$ do Programa de Mestrado em Tecnologias Limpas e do Departamento de

Agronomia/ Centro Universitário Cesumar - Unicesumar, campus Maringá - PR,

Brasil. Pesquisadora do Instituto Cesumar de Ciência, Tecnologia e Inovação (ICETI).

${ }^{4}$ Prof ${ }^{\mathrm{a}}$. Ms. do Departamento de Agronomia/ Centro Universitário Cesumar Unicesumar, campus Maringá - PR, Brasil.

${ }^{5}$ Prof $^{a}$. Dr ${ }^{a}$ do Programa de Mestrado em Tecnologias Limpas e do Departamento de Agronomia/ Centro Universitário Cesumar - Unicesumar, campus Maringá - PR,

Brasil. Pesquisadora do Instituto Cesumar de Ciência, Tecnologia e Inovação (ICETI). (edneia.paccola@unicesumar.br).

\section{Recebido em: 08/04/2017 - Aprovado em: 10/06/2017 - Publicado em: 20/06/2017 DOI: 10.18677/EnciBio 2017A89}

\section{RESUMO}

O objetivo do trabalho foi avaliar a qualidade de lotes de sementes certificadas e não certificadas de Phaseolus vulgaris, analisando os componentes físicos, fisiológicos e sanitários, visando a sustentabilidade da cadeia produtiva da cultura. O ensaio foi conduzido sob delineamento inteiramente casualizado, com quatro repetições. Foram comparados dois lotes de sementes certificadas da cultivar IPR Tangara e IAC Imperador e dois lotes não certificadas das mesmas cultivares. As amostras de sementes foram submetidas a análise de pureza, e testes de germinação indireto, tetrazólio, frio e de sanidade, além de exame de sementes infestadas/danificadas por insetos. Os dados foram submetidos à análise de variância e as médias comparadas pelo teste de Tukey a 5\%. As sementes certificadas apresentaram maiores taxas de germinação com 92,50\% (IAC Imperador certificada) e 89,5\% (IPR Tangará certificada), enquanto para não certificadas as porcentagens foram $49 \%$ e $62,5 \%$ para IPR Tangará e IAC Imperador, respectivamente. Além disso, as sementes certificadas foram mais vigorosas quando submetidas ao teste de tetrazólio com 88\% (IPR Tangará certificada) e 87\% (IAC Imperador certificada), contudo as não certificadas alcançaram $66 \%$ e $59 \%$ para IPR Tangará e IAC Imperador, respectivamente. Não foram detectados danos decorrentes da ação de insetos, porém, o teste de sanidade mostrou que todos os lotes estavam contaminados por patógenos, sendo que a cultivar IPR Tangará certificada apresentou o menor índices de contaminação (32,2\%). Os lotes de sementes certificadas e não certificadas exibiram respostas diferentes para as variáveis 
mensuradas, e de modo geral, as sementes certificadas apresentaram melhor desempenho.

PALAVRAS- CHAVE: Agricultura sustentável. Feijoeiro. Sementes.

\title{
QUALITY OF Phaseolus vulgaris L. SEEDS IN THE CONTEXT OF SUSTAINABILITY
}

\begin{abstract}
The main objective of this work was to evaluate the quality of certified and uncertified Phaseolus vulgaris seed lots, assessing physical, physiologic and sanitary components, aiming to the sustainability of the productive chain of the culture. The assay was made under a completely randomized design with four repetitions. It were compared two certified seed lots from cultivars IPR Tangara and IAC Imperador and two uncertified lots from the same cultivars. The seed samples were submitted to purity analysis and indirect germination tests, tetrazolio, cold and sanity, and also to examination of insect infected/damaged seeds. Data were submitted to variance analysis and the averages were compared by Tukey test with $5 \%$. The certified seeds presented higher germination rates with 92,50\% (certified IAC Imperador) and $89,5 \%$ (certified IPR Tangara), while uncertified the percentages were $49.0 \%$ and $62.5 \%$ for IPR Tangara and IAC Imperador, respectively. Besides, certified seeds were more vigorous when submitted to tetrazolio test with $88 \%$ (certified IPR Tangara) and $87 \%$ (certified IAC Imperador), however uncertified obtained $66.0 \%$ and $59.0 \%$ for IPR Tangara and IAC Imperador, respectively and also in the cold test. It wasn't detected insect damages, however, the sanity test showed that all lots were contaminated with pathogens, and that the certified cultivar IPR Tangara presented the smaller contamination index (32,2\%). The certified and uncertified seed lots showed different responses to the measured variables and, in general, certified seeds presented better performance.
\end{abstract}

KEYWORDS: Seeds. Common bean. Sustainable agriculture.

\section{INTRODUÇ̃̃O}

O feijoeiro comum (Phaseolus vulgaris L.) é consumido mundialmente, sendo culturalmente importante para a nutrição humana (FAO, 2014). Na América Latina e na África Oriental o feijão é considerado um dos alimentos básicos da população (ASTUDILLO-REYES et al., 2015; SANTOS et al., 2015), os grãos são constituídos de proteína (23\%), carboidrato complexo, fibras, algumas vitaminas e minerais (CAMPOS-VEGA et al., 2013). Diante da importância social e econômica da cultura do feijoeiro, o alcance de altos níveis de produtividade torna-se fundamentalmente importante (BINOTTI et al., 2009).

A utilização de sementes de qualidade é um dos fatores que mais contribui para a obtenção de altas produtividades nas culturas agrícolas (AMARO et al., 2015). Contudo, estima-se que aproximadamente $89 \%$ dos produtores brasileiros de feijão utilizam grãos próprios para a semeadura (MICHELS et al., 2014; SILVA, 2015), tornando os plantios mais susceptíveis as condições adversas.

A qualidade fisiológica da semente esta relacionada com a capacidade em desempenhar suas funções vitais (KAPPES et al., 2012; CARDOSO et al., 2012). Sendo que, a avaliação do potencial fisiológico é o principal componente de controle de qualidade, considerando que as informações geradas auxiliam na resolução de 
problemas durante o processo de produção, além de estimar o desempenho da semente no campo (MARTINS et al., 2014).

Portanto, os efeitos da má qualidade geralmente são traduzidos pelo decréscimo na porcentagem de germinação, aumento de plântulas anormais e redução do vigor das plântulas (FRANÇA-NETO et al., 2010), culminado com a queda da produtividade.

Segundo CARVALHO (2012) lotes de sementes com baixa pureza e qualidade sanitária inferior não afetam apenas a produtividade da cultura, mas também a sustentabilidade ambiental e econômica deste agrossistema. Isto porque a presença de sementes de plantas daninhas, agentes causais de doenças e pragas tem influência negativa para o estabelecimento da cultura no campo. Como por exemplo, a redução da germinação, perdas no estande e vigor das plântulas, redução no rendimento da produção (DUBE et al., 2015) e ainda atuam como fonte de inóculo primário de patógenos (MACHADO, 2010; CARVALHO \& NAKAGAWA, 2012), que levam ao aumento da aplicação de defensivos químicos, onerando os custos da produção e desencadeando problemas ambientais (CARVALHO, 2012).

Em decorrência da aplicação indiscriminada de defensivos vários problemas ambientais têm sido constatados, podendo estes ter consequências graves em longo prazo e seus efeitos em muitos casos são irreversíveis (BOHNER et al., 2013). Ademais, esta prática pode causar perdas na qualidade dos recursos hídricos (DELLAMATRICE \& MONTEIRO, 2014) e dos solos, culminando em alterações significativas nos ecossistemas.

No entanto, as implicações associadas ao uso de defensivos poderiam ser minimizadas, caso as sementes apresentassem um perfil de qualidade sanitária, física e genética dentro de padrões aceitáveis, atrelando desta forma, vantagens econômicas e ambientais, devido a diminuição do uso de produtos químicos e a redução dos custos de produção. Alguns trabalhos com sementes de feijoeiro têm sido realizados visando a avaliação da qualidade fisiológica (CASSOL et al., 2012; SILVA et al., 2014; MICHELS et al., 2014; PARREIRA et al., 2015; ZUCARELI et al., 2015 ), sanitária (ALMEIDA et al., 2013; BRITO et al., 2013); e física (MOTA, 2016). No entanto, poucas informações estão disponíveis sobre avaliações simultâneas entre sementes certificadas e não certificadas, para os diferentes aspectos que abrangem sementes de alta qualidade.

Diante disso, o objetivo do trabalho foi avaliar a qualidade de diferentes lotes de sementes certificadas e não certificadas de Phaseolus vulgaris, analisando os componentes físicos, fisiológicos e sanitários, visando à sustentabilidade da cadeia produtiva desta cultura.

\section{MATERIAL E MÉTODOS}

O trabalho foi conduzido no Laboratório de Sementes da Unicesumar. Para as análises utilizaram quatro lotes de sementes de feijão carioca, sendo: i) semente certificada do cultivar IPR Tangará; ii) semente não certificada do cultivar IPR Tangará; iii) sementes certificada do cultivar IAC Imperador; iv) semente não certificada do cultivar IAC Imperador. As amostras foram submetidas a diferentes testes para avaliação e comparação da pureza física, qualidade fisiológica e sanitária das sementes.

Análise de pureza: para cada um dos quatro lotes foi obtida uma amostra de trabalho a partir da homogeneização e divisão das amostras médias, até se obter $700 \mathrm{~g}$ de sementes. A amostra obtida foi espalhada sobre a bancada, e com 0 
auxílio de pinça e estereomicroscópio, as sementes foram examinadas conforme descrição de BRASIL (2009). Posteriormente foram separadas (semente pura, outras sementes e material inerte) e pesadas com a finalidade de se definir a porcentagem de pureza do lote de sementes. De modo que, a porção "semente pura" foi então reservada para realização dos demais testes.

Teste de Germinação: para a montagem do experimento utilizaram-se quatro repetições de 50 sementes, perfazendo 200 sementes para cada lote. As sementes foram distribuídas sobre duas folhas de papel "germitest", previamente umedecidas com quantidade de água equivalente a 2,5 vezes o peso do papel seco. Em seguida, cobertas com mais uma folha de papel, formando rolos que foram distribuídos em germinador regulado à temperatura constante de $25^{\circ} \mathrm{C}$ e luz constante (Figura $1, \mathrm{~A}$ ). As avaliações foram realizadas no quinto e nono dia após a instalação do teste e os resultados expressos em porcentagem de plântulas normais, conforme Regras para Análise de Sementes - RAS (BRASIL, 2009).
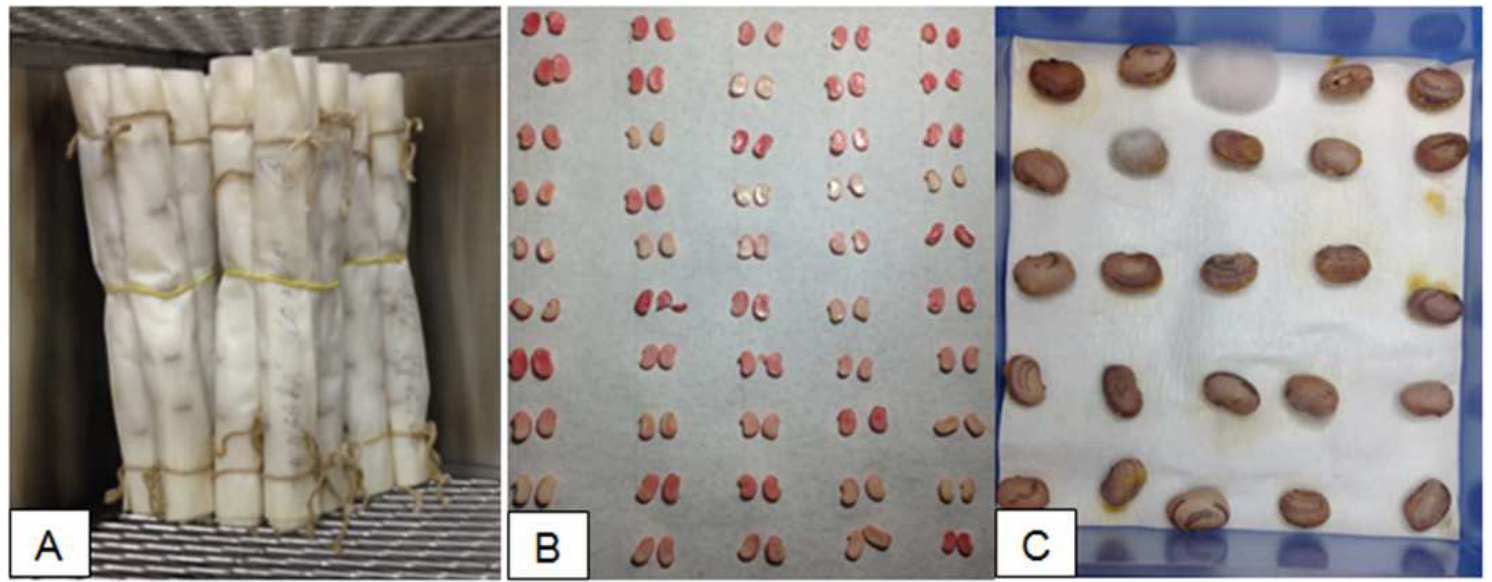

FIGURA 1. Teste de germinação de sementes em substrato de papel (A). Sementes submetidas ao teste de tetrazólio (B). Teste de sanidade de sementes conduzido pelo método do papel filtro ("blotter test")

Teste de Tetrazólio: para este teste foram utilizadas duas repetições de 50 sementes para os diferentes lotes. Primeiramente, as sementes foram distribuídas em caixas gerbox, entre duas folhas de papel umedecidas com quantidade de água equivalente a três vezes a massa seca do mesmo, em seguida incubados no germinador regulado a $25^{\circ} \mathrm{C}$ durante 16 horas. Para o desenvolvimento da coloração, as sementes foram transferidas para Becker e submersas com uma solução de cloreto de 2, 3, 5 trifenil tetrazólio a $0,075 \%$ ( $p / v)$ e incubadas na temperatura de $37^{\circ} \mathrm{C}$, na ausência de luz, durante 120 minutos. Após este período, as sementes foram lavadas em água corrente e com auxílio de bisturi, e seccionadas longitudinalmente ao longo do eixo embrionário e os tegumentos removidos (Figura 1, B). As sementes foram analisadas individualmente em estereomicroscópio com iluminação fluorescente, observando a parte externa e interna, os tipos de danos ocorridos, sua localização e extensão e posteriormente classificadas de acordo com o nível de vigor de acordo com as classes estabelecidas por BHERING et al., (1999). 
Teste de Frio: conduzido mediante o método do rolo de papel sem solo, conforme a metodologia descrita por BARROS et al. (1999), utilizando-se quatro repetições com 50 sementes de cada lote, perfazendo 200 sementes. Estas foram previamente desinfestadas com solução de hipoclorito de sódio a $1 \%$ durante três minutos, e em seguida distribuídas sobre duas folhas de papel filtro, umedecidas com água destilada em uma proporção de três vezes o peso do papel seco. As sementes foram cobertas com mais uma folha de papel filtro, confeccionando-se os rolos, colocados dentro de sacos plásticos e acondicionados a $10^{\circ} \mathrm{C}$ durante cinco dias. Decorrido este período os sacos então retirados e os rolos colocados em germinador regulado a temperatura de $25^{\circ} \mathrm{C}$ por mais cinco dias. Os resultados foram expressos em porcentagem de plântulas normais.

Exame de sementes infestadas e/ou danificadas por insetos: a avaliação de sementes infestadas foi realizada de acordo com os parâmetros definidos por BRASIL (2009). Para tanto, foram retiradas ao acaso duas repetições de 100 sementes de cada lote da amostra média. Cada amostra foi analisada com auxílio de uma pinça e estereomicroscópio, das quais inicialmente foram analisadas secas, com a finalidade de observar orifícios de saída de insetos. As sementes perfuradas foram contabilizadas e descartadas. Posteriormente, o restante da amostra foi mergulhada em água durante 14 horas para amolecer as sementes, e com o uso de um bisturi as mesmas foram seccionadas individualmente para observação das estruturas internas e verificação da presença de ovo, larva, lagarta, pupa ou insetos adultos. $O$ número de sementes infectadas foi somado com o registrado para sementes perfuradas obtendo-se o resultado final, calculado a partir da média das sementes danificadas das duas repetições e expresso em porcentagem.

Teste de sanidade de sementes: $O$ teste de sanidade foi conduzido pelo método do papel de filtro ("blotter test"), com congelamento (Figura 1, C). Para tanto, utilizaram-se 400 sementes de cada lote, obtidas da porção da semente pura, perfazendo 16 repetições de 25 sementes. As sementes foram previamente desinfestadas com hipoclorito de sódio a 1\% por 3 minutos e dispostas em gerbox sobre três folhas de papel filtro (autoclavadas), embebidas em água destilada esterilizada na razão de três vezes o peso do papel. Posteriormente, foram incubados a $20^{\circ} \mathrm{C} \pm 2^{\circ} \mathrm{C}$, sob regime de $12 \mathrm{~h}$ de luz (fluorescente)/12h escuro por 24 horas, seguido do acondicionamento a $-18 \stackrel{\circ}{\circ}$ por 24 horas com objetivo de inibir a germinação. Após tratamento térmico, os grãos foram novamente incubados na temperatura e luminosidade anteriormente citada $\left(20^{\circ} \mathrm{C} \pm 2^{\circ} \mathrm{C}\right.$, fotoperíodo $\left.12 / 12 \mathrm{~h}\right)$ durante cinco dias. Decorrido o período de incubação, as sementes foram examinadas individualmente com auxílio de estereomicroscópio, observando a presença de colônias bacterianas, e frutificações e micélios típicos de fungos. Sendo que, os fungos mais frequentemente observados foram isolados e identificado em nível de gênero através da visualização das suas estruturas em microscópio óptico.

Procedimento estatístico: $O$ delineamento experimental utilizado para todos os testes foi o inteiramente casualizado (DIC). Os resultados foram submetidos à análise de variância e as médias comparadas pelo teste de Tukey a 5\%, com auxilio do programa SISVAR (FERREIRA, 2011). 


\section{RESULTADOS E DISCUSSÃO}

Os resultados da análise de pureza mostraram que todos os lotes avaliados estavam com índices acima de $98 \%$ para fração pura (Tabela 1), ou seja, todos os lotes encontraram-se dentro do recomentado para a comercialização de sementes, cujo mínimo aceito é de $98 \%$ (BRASIL, 2009).

TABELA 1. Análise de pureza de diferentes lotes de sementes certificadas e não certificadas do feijoeiro (Phaseolus vulgaris).

\begin{tabular}{lccc}
\hline \multicolumn{1}{c}{ Cultivar } & $\begin{array}{c}\text { Outras } \\
\text { sementes }(\%)\end{array}$ & $\begin{array}{c}\text { Material inerte } \\
(\%)\end{array}$ & Pureza (\%) \\
\hline IPR Tangará Certificada & $0,00 \mathrm{a}$ & $0,17 \mathrm{~b}$ & 99,83 \\
IPR Tangará não Certificada & $0,19 \mathrm{c}$ & $1,29 \mathrm{~d}$ & 98,52 \\
IAC Imperador Certificada & $0,00 \mathrm{a}$ & $0,03 \mathrm{a}$ & 99,97 \\
IAC Imperador não Certificada & $0,08 \mathrm{~b}$ & $1,15 \mathrm{c}$ & 98,77 \\
\hline
\end{tabular}

Fonte: autores.

No que tange a pureza física de sementes, fatores como o manejo na colheita, beneficiamento e armazenamento inadequado (LOPES et al., 2011), podem interferir de maneira negativa. Porém para os lotes avaliados essas etapas foram conduzidas de forma adequada, justificando a baixa presença de material inerte e de outras sementes. Resultados semelhantes foram encontrados por SILVA (2015) que avaliou sementes salvas de feijão-caupi de diferentes origens e verificou que a pureza física variou entre $97,1 \%$ a $100 \%$, constatando que apenas $5 \%$ das amostras apresentaram índices de pureza inferior ao recomendado pela legislação (98\%).

Ainda que, os lotes de sementes apresentaram padrões de pureza dentro do recomendado, foi observado que o lote IPR Tangará não Certificada e IAC Imperador não Certificada, quando comparadas com sementes certificadas apresentaram diferenças estatísticas significativas para a presença de outras sementes, com índices de 0,19\% e 0,08\%, respectivamente (Tabela 1). Em estudo realizado por SILVA (2015) com diferentes amostras de feijão-caupi, os resultados mostraram que das 37 amostras analisadas $45 \%$ apresentaram contaminações com sementes de outras espécies cultivadas e por sementes de cultivares diferentes da mesma espécie, porém, independentemente das amostras analisadas, todas estiveram isentas de sementes nocivas proibidas.

De modo geral, a principal implicação para o uso de sementes com presença de sementes de outras espécies, ou seja, com baixo grau de pureza, reside no fato de que as mesmas podem veicular sementes de espécies de plantas nocivas (ISTA, 2007). Assim, o emprego de sementes puras visa prevenir a introdução, estabelecimento ou disseminação principalmente de plantas daninhas (FERREIRA, 2006), com isso os custos de produção podem diminuir em função da redução da necessidade de aplicação de herbicidas e, consequentemente, minimizarem os impactos ambientais decorrentes da aplicação dos mesmos.

Neste trabalho, apesar de todos os lotes estarem dentro do padrão estabelecido pelos órgãos regulamentadores, cabe ressaltar que o uso de sementes certificadas reduz o risco de infestação por plantas daninhas na cultura, reduzindo o uso de agroquímicos e os impactos ambientais.

Com relação à presença de material inerte, todos os lotes apresentaram diferenças significativas (Tabela 1). No entanto, foi possível observar que os lotes de 
IPR Tangará não Certificada e IAC Imperador não Certificada os valores foram de $1,29 \%$ e 1,15\% respectivamente, enquanto para os lotes IPR Tangará Certificada e IAC Imperador Certificada foram de $0,17 \%$ e $0,03 \%$, respectivamente, ou seja, as sementes certificadas tiveram menor presença de material inerte em comparação às sementes não certificadas.

Para a variável germinação, a porcentagem da primeira contagem foi inferior em relação à germinação final (Tabela 02), possivelmente parte das sementes duras da primeira contagem germinou tardiamente aumentando o percentual da germinação. Resultados semelhantes foram encontrados por SANTOS et al. (2015), que avaliaram quatro cultivares de feijão carioca verificando o aumento da germinação de sementes da primeira contagem em relação a porcentual final do teste de germinação.

TABELA 2. Teste de germinação, tetrazólio e frio para diferentes lotes de sementes certificadas e não certificadas de feijão (Phaseolus vulgaris).

\begin{tabular}{lcccc}
\hline \multicolumn{1}{c}{ Cultivar } & $\begin{array}{c}\text { Germinação } \\
5^{\circ} \text { dia (\%) }\end{array}$ & $\begin{array}{c}\text { Germinação } \\
9^{\circ} \text { dias (\%) }\end{array}$ & $\begin{array}{c}\text { Teste } \\
\text { tetrazólio } \\
(\%)\end{array}$ & $\begin{array}{c}\text { Teste frio } \\
(\%)\end{array}$ \\
\hline $\begin{array}{l}\text { IPR Tangará Certificada } \\
\text { IPR Tangará não }\end{array}$ & $81,50 \mathrm{a}$ & $89,50 \mathrm{a}$ & $88,00 \mathrm{a}$ & $85,50 \mathrm{a}$ \\
Certificada & $45,50 \mathrm{~b}$ & $49,00 \mathrm{~b}$ & $66,00 \mathrm{~b}$ & $47,50 \mathrm{~b}$ \\
IAC Imperador Certificada & $92,00 \mathrm{a}$ & $92,50 \mathrm{a}$ & $87,00 \mathrm{a}$ & $82,00 \mathrm{a}$ \\
IAC Imperador não & $62,00 \mathrm{c}$ & $62,50 \mathrm{~b}$ & $59,00 \mathrm{~b}$ & $48,00 \mathrm{~b}$ \\
Certificada & 9,37 & 9,08 & 8,70 & 5,50 \\
\hline${ }^{*}$ CV\% & & & & \\
\hline
\end{tabular}

Fonte: Autores. ${ }^{*} \mathrm{CV}=$ Coeficiente de variação.

O resultado da germinação confirmou o desempenho superior das sementes do lote Imperador certificado, por apresentarem maiores porcentagens de plântulas normais $92,50 \%$ (Tabela 2 ), enquanto que o lote não certificada da mesma cultivar alcançou 62,5\% (Tabela 2), cabe ressaltar que apesar de não ter sido constatado diferenças estatísticas entre as duas cultivares (IPR Tangará e IAC Imperador), foi possível verificar que tanto as sementes certificadas como as não certificadas da IAC Imperador apresentaram maiores porcentagens de germinação quando comparadas com as correspondentes da IPR Tangará.

O mesmo pode ser observado para IPR Tangará Certificada quando comparada com o lote IPR Tangará não Certificada, em que o índice de plântulas normais foi de $89,5 \%$ e 49\%, respectivamente (Tabela 2). AMARO et al., (2015) analisando cinco lotes das sementes de feijoeiro da cultivar madrepérola observaram que todas apresentação germinação acima de $80 \%$.

Assim, observaram-se diferenças estatísticas significativas entre ambos os lotes de sementes certificadas em relação as suas correspondentes não certificadas (Tabela 2), de modo que, o menor potencial germinativo das sementes não certificadas pode comprometer o estabelecimento de estande desejado de plantas no campo. Além disso, segundo MAPA (2013), a exigência mínima de germinação para certificação de um lote de sementes de feijão é de $80 \%$, portanto, os lotes de sementes não certificadas seriam descartados para fins propagativos.

Os resultados para o parâmetro vigor de sementes obtidos pelo teste de tetrazólio apontaram que não houve diferença estatística entre os dois lotes de 
sementes certificadas, porém, diferenças significativas foram encontradas entre sementes certificas e não certificadas (Tabela 2), em que, o vigor da IPR tanguará certificada foi de $88 \%$ e a IPR tanguará não certificada $66 \%$. Por sua vez, para o lote Imperador os índices foram de $87 \%$ e $59 \%$ para certificadas e não certificada, respectivamente (Tabela 2 ). Deste modo, verificou-se que ambos os lotes de sementes não certificadas apresentaram vigor reduzido. A perda de vigor das sementes pode ser ocasionada por diferentes fatores, segundo FILHO (2005) o vigor pode ser influenciado pelo ataque de pragas e doenças, pelas características do genótipo, condições climáticas, que ocorrem durante o ciclo de desenvolvimento da semente.

Ademais, sementes de Phaseolus vulgaris L. são altamente sensíveis às condições de ambiente e ao manejo, durante e após a colheita, apresentando muitas vezes baixa qualidade fisiológicas (KRZYZANOWSKI et al.,1999). Este fato foi evidenciado por ZUCARELI et al., (2015) que constataram que a qualidade fisiológica das sementes de feijão carioca foi reduzida durante o armazenamento para diferentes lotes avaliados, porém com taxas mais acentuadas sob condições não controladas de temperatura e umidade.

Quanto aos resultados para o teste de frio o lote IPR Tangará certificada apresentou $85,5 \%$ de plântulas normais, enquanto para o lote IPR Tangará não Certificada foi $47,5 \%$. Os lotes IAC Imperador certificada e não Certificada, atingiram respectivamente $82 \%$ e $48 \%$ de plântulas normais (Tabela 2). Segundo KRZYZANOWSKI (1999), é considerado aceitável para o controle de qualidade, um desempenho no teste de frio superior ou igual ao valor mínimo do padrão para o teste de germinação. O MAPA (2013) estabelece uma germinação mínima de $80 \%$ para certificação de sementes de feijão.

Considerando que, o teste de frio avalia a resposta das amostras a combinações de estresses, como baixas temperaturas e alto teor de umidade, em função da sobrevivência da semente ser diretamente proporcional ao grau de vigor (NASCIMENTO, 2009), e que os lotes de sementes certificadas neste estudo, exibiram vigor acima a $80 \%$, os resultados sugerem que possivelmente os lotes certificados teriam desempenho superior para o estabelecimento da cultura no campo quando comparadas com sementes não certificadas, ou seja, as sementes certificadas podem ser consideradas mais aptas para formar plântulas com maior tolerância a estresses.

Com relação ao exame de sementes infestadas e/ou danificadas por insetos, nas amostras analisadas não foram encontradas evidências de sementes danificadas. Desse modo, as sementes certificadas e não certificadas apresentaram $0 \%$ de infestação (Tabela 3). Segundo o MAPA (2013), para certificação das sementes de feijão é tolerado até $3 \%$ de sementes infestadas. Portanto, todos os lotes estavam dentro dos parâmetros estabelecidos para este quesito. Cabe ressaltar que a avaliação regular da predação da semente é importante para atestar sua qualidade, pois afeta a qualidade nutricional dos grãos, redução na germinação e perdas econômicas graves (DE-SÁ et al., 2014). 
TABELA 3. Porcentagem de sementes infestadas e/ou danificadas por insetos e sementes contaminadas por patógeno.

\begin{tabular}{lcc}
\hline \multicolumn{1}{c}{ Cultivar } & $\begin{array}{c}\text { Sementes } \\
\text { Infestadas }(\%)\end{array}$ & $\begin{array}{c}\text { Sementes contaminadas por } \\
\text { patógenos }(\%)\end{array}$ \\
\hline IPR Tangará Certificada & $0,0 \mathrm{a}$ & $32,2 \mathrm{a}$ \\
IPR Tangará não Certificada & $0,0 \mathrm{a}$ & $94,2 \mathrm{c}$ \\
IAC Imperador Certificada & $0,0 \mathrm{a}$ & $52,7 \mathrm{~b}$ \\
IAC Imperador não Certificada & $0,0 \mathrm{a}$ & $59,7 \mathrm{~b}$ \\
\hline CV \% & 0,0 & 14,9 \\
\hline
\end{tabular}

Fonte: autores . ${ }^{*} \mathrm{CV}=$ Coeficiente de variação.

BRAGANTINI (2005), afirmou que os grãos são infestados por insetos ainda no campo e podem ser levados para o ambiente de armazenamento. Assim, ELIAS (2008) defende que condições adequadas de armazenagem, como baixa umidade dos grãos e baixas temperaturas desaceleram o desenvolvimento de pragas. Portanto, com base nos resultados encontrados neste estudo é possível afirmar que as sementes de todos os lotes chegaram do campo livres de pragas e, ainda que 0 armazenamento realizado no laboratório de sementes não permitiu a contaminação e proliferação dos insetos.

Por sua vez, os fatores sanitários se destacam pelo efeito deletério provocado pela ocorrência de micro-organismo e insetos associados às sementes, desde o campo até o armazenamento (FACCION, 2011). SOUZA et al., (2013) afirmam que a capacidade germinativa é comumente afetada por patógenos presentes tanto no interior como na sua superfície das sementes.

No teste de sanidade de semente verificou-se a presença de microorganismos em todos os lotes analisados, porém com frequências distintas. Sendo patógenos fúngicos mais incidentes nos lotes do cultivar IPR Tangará, enquanto que os lotes do cultivar IAC Imperador apresentaram maior incidência bacteriana.

O lote de semente IPR Tangará certificada apresentou a menor incidência de patógenos entre os lotes avaliados, com $32 \%$ de sementes contaminadas (Tabela 3), por outro lado, para o IPR Tangará não certificado os índices foram elevados alcançando $94 \%$ de incidência. No entanto, não foram observadas diferenças estatísticas significativas entre os lotes certificados e não certificados da cultivar Imperador, embora as sementes não certificadas tivessem apresentado incidência mais alta de patógenos.

As diferenças observadas entre as cultivares pode ter sido em função das características genotípicas (COELHO et al., 2010), ou ainda pelo manejo da colheita, pois, durante a colheita, a semente fica suscetível ao dano mecânico (LOPES et al., 2011) aumentando a suscetibilidade a micro-organismos, reduzindo o vigor e a germinação.

Os fungos mais frequentes em todos os lotes analisados neste trabalho foram os gênero Penicillium sp. e Aspergillus sp. Resultados semelhantes foram encontrados por FACCION (2011) em que foram detectados a presença de Fusarium sp., Penicillium sp. e Aspergillus sp. em sementes de feijão nas diferentes etapas de beneficiamento. ALMEIDA et al., (2013) avaliaram cinco cultivares de feijão comum, e verificaram que os gêneros mais frequentes foram Fusarium sp. e Aspergillus. De acordo com CARVALHO \& NAKAGAWA (2012) fungos de armazenamento como Aspergillus e Penicillium podem causar danos nas sementes, como perda do poder germinativo e morte do embrião, apodrecimento da semente, 
culminando com a deterioração. Além disso, em condições favoráveis, alguns gêneros de fungos de armazenamento produzem substâncias toxicas para seres humanos e animais, com implicações negativas a saúde publica e a economia e a economia (HEIDTMANN-BEMVENUTI et al., 2011; MARTINEZ et al., 2014; LIMA et al., 2015; MOTTA et al., 2015), podendo causar contaminações ambientais, no solo (HARTMANN et al., 2008) e na água (KOLPIN et al., 2014; RIBEIRO \& TIRITAN, 2015).

Dada à importância, da qualidade sanitária de sementes de feijão cabe ressaltar que esse fator destaca-se entre as medidas mais importantes no manejo fitossanitário, por prevenir inúmeras doenças no campo. O uso de sementes com qualidade sanitária garantida, além da qualidade genética, física e fisiológica, é a maneira mais simplificada e econômica de reduzir custos de produção e assegurar sustentabilidade dos cultivos (MACHADO, 2010).

Portanto, os resultados obtidos neste trabalho sugerem que cultivos derivados de sementes não certificadas podem apresentar menor stand de plantas no campo, plantas com menor vigor e maior probabilidade de ocorrência de epidemias ocasionadas por patógenos veiculados por sementes, necessitando de maior controle fitossanitário. Assim, o uso de sementes certificadas constitui uma das práticas que garante sustentabilidade para o manejo da cultura tanto no âmbito ambiental como econômico.

\section{CONCLUSÃO}

Os resultados obtidos demonstram que os lotes de sementes certificadas apresentam qualidade superior em relação a sua pureza, sanidade, vigor e potencial de germinação em relação aos lotes de sementes não certificadas avaliados.

Ademais, a utilização de sementes certificadas contribui na busca da sustentabilidade deste agrossistema ocasionando menor impacto ambiental e econômico no cultivo do feijão.

\section{REFERÊNCIAS}

ALMEIDA, A. P. V.; SILVA, E.; SILVA, V. P.; ZAGO, B. W.; OLIVEIRA, B. S. Qualidade física, fisiológica e sanitária de sementes de feijoeiro (Phaseolus vulgaris I.) provenientes do município de Tangará da Serra - MT. Enciclopédia Biosfera, v.9, n.17, p.2241-2249, $2013 . \quad$ Disponível em: <http://www.conhecer.org.br/enciclop/2013b/CIENCIAS\%20AGRARIAS/qualidade\%2 Ofisica.pdf $>$.

AMARO, H. T. R.; DAVID, A. M. S. S.; ASSIS, M. O.; RODRIGUE, B. R. A.; CANGUSSÚ, L. V.S.; OLIVEIRA, M. B. Testes de vigor para avaliação da qualidade fisiológica de sementes de feijoeiro. Revista de Ciências Agrárias, v. 38, n. 3, p. 383-389, 2015.2 Disponível em: <http://www.scielo.mec.pt/scielo.php?script=sci_arttext\&pid=S0871-

018X2015000300013\&lng=pt\&nrm=iso >.

ASTUDILLO-REYES, C.; FERNANDEZ, A. C.; CICHY, K. A. Transcriptome Characterization of Developing Bean (Phaseolus vulgaris L.) Pods from Two Genotypes with Contrasting Seed Zinc Concentrations. PloS one, v. 10, n 9, p. 137157, 2015. Disponível em: <http://dx.doi.org/10.1371/journal.pone.0137157>. doi:10.1371/journal.pone.0137157 
BARROS, A. S. R.; DIAS, M. C. L. L.; CICERO, S. M.; KRZYZANOWSKI, F. C. Testes de frio. In: KRZYZANWSKI, F. C.; VIEIRA, R.D.; FRANÇA-NETO, J. B. (Eds.). Vigor de sementes: conceitos e testes. Londrina: ABRATES, 1999. p. 1-15.

BHERING, M. C.; SILVA, R.F.; ALVARENGA, E.M.; DIAS, D.C.F.S.; PENA, M. F. Metodologia do teste de tetrazólio em sementes de feijão. In: KRZYZANOWSKI, F.C.; VIEIRA, R.D.; FRANÇA NETO, J.B. (eds.). Vigor de sementes: conceitos e testes. Londrina: ABRATES, p. 8.3-1 - 8.3-10. 1999.

BINOTTI, F. F. S.; ARF, O.; SÁ, M. E.; BUZETTI, S.; ALVAREZ, A. C. C.; KAMIMURA, K. M. Fontes, doses e modo de aplicação de nitrogênio em feijoeiro no sistema plantio direto. Bragantia, v. 68, n. 2, p. 473-481, 2009. Disponível em: <http://dx.doi.org/10.1590/S0100-06832009000100023>. doi: 10.1590/S010006832009000100023

BOHNER, T. O. L.; ARAÚJO, L. E. B.; NISHIJIMA, T. O. Impacto ambiental do uso de agrotóxicos no meio ambiente e na saúde dos trabalhadores rurais. Revista Eletrônica do Curso de Direito, v. 8, edição especial, p. 329-341, 2013. Disponível em: <http://dx.doi.org/10.5902/198136948280>. doi: 10.5902/19813694

BRAGANTINI, C. Alguns aspectos do armazenamento de sementes e grãos de feijão. Embrapa Arroz e Feijão, 2005. 28, p. 11. Disponível em: <http://www.cnpaf.embrapa.br/transferencia/informacoestecnicas/publicacoesonline/ seriedocumento12 s_187.pdf>

BRASIL, Ministério da Agricultura e Reforma Agrária. Regras para análise de sementes. Brasília, DF, 2009. 365 págs. Disponível em:< http://www.agricultura.gov.br/arq_editor/file/2946_regras_analise_sementes. pdf $>$.

BRITO, R.; LOPES, H.; ARAÚJO-FERNANDES, M.; DE AGUIAR, L.; CEARÁ, P. Avaliação da qualidade fisiológica e sanitária de sementes de feijão-vagem (Phaseolus vulgaris L.) produzidas sob manejo orgânico e submetidas ao congelamento. Revista Brasileira De Agroecologia, v. 8, n.3, 2013. Disponível em: $<$ http://www.aba-

groecologia.org.br/revistas/index.php/rbagroecologia/article/view/13263/9906>

CAMPOS-VEGA, R.; OOMAH, D.; LOARCA-PIÑA, G.; VERGARA-CASTAÑEDA, $\mathrm{H}$. A. Common beans and their non-digestible fraction: cancer inhibitory activity: an overview. Foods, v. 2, n. 3, p. 374-392, 2013. Disponível em: <http://www.mdpi.com/2304-8158/2/3/374/htm>. doi:10.3390/foods2030374

CARDOSO, R. B.; BINOTTI, F. F. da S.; CARDOSO, E. D. Potencial fisiológico de sementes de crambe em função de embalagens e armazenamento. Pesquisa Agropecuária Tropical, v. 42, n. 3, p. 272-278, 2012. Disponível em: https://www.revistas.ufg.br/pat/article/view/17249.

CARVALHO, N. M.; NAKAGAWA, J.; Sementes: ciência, tecnologia e produção. 5 ed., Jaboticabal: Funep, 2012. 590p. 
CASSOL, F. D. R.; FORTES, A. M. T.; JNUNES, J. V. D.; VEIT, M. R.; CRUZ, M. Qualidade fisiológica de lotes de sementes de feijão em função do armazenamento. Cultivando o Saber. Cascavel, v.5, n.2, p.85-97, 2012. Disponível em:< http://www.fag.edu.br/upload/revista/cultivando_o_saber/503fb35a6e010.pdf>

COELHO, C. M. M.; MOTA, M.R.; SOUZA, C. A. E.; MIQUELLUTI, D. J. Potencial fisiológico em sementes de cultivares de feijoeiro crioulo (Phaseolus vulgaris L.). Revista Brasileira de Sementes, v. 32, n. 3, p. 097-105, 2010. Disponível em: <http://dx.doi.org/10.1590/S0101-31222010000300011>. doi 10.1590/S010131222010000300011

DELLAMATRICE, P. M.; MONTEIRO, R. T. R. Principais aspectos da poluição de rios brasileiros por pesticidas. Revista Brasileira de Engenharia Agrícola e Ambiental, v.18, p.1296-1301, 2014. Disponível em: <http://dx.doi.org/10.1590/1807-1929/agriambi.v18n12p1296-1301>. doi: 10.1590/1807-1929/agriambi.v18n12p1296-1301

DE SÁ, L. F. R.; WERMELINGER, T. T.; RIBEIRO, E. S.; GRAVINA, G. A.; FERNANDES, K. V. S.; XAVIER-FILHO, J.; VENANCIO, T. M.; REZENDE, G. L.; OLIVEIRA, A. E. A. Effects of Phaseolus vulgaris (Fabaceae) seed coat on the embryonic and larval development of the cowpea weevil Callosobruchus maculatus (Coleoptera: Bruchidae). Journal of Insect Physiology, v. 60, p. 50-57, 2014. Disponível em: <https://www.ncbi.nlm.nih.gov/pubmed/24211390>. doi: 10.1016/j.jinsphys.2013.10.004

DUBE, E.; SIBIYA, J.; FANADZO, M. Early planting and hand sorting effectively controls seed-borne fungi in farmretained bean seed. South Africa Journal of Science, v. 110, n. 11, p.1- 12, 2014. Disponível em: http://dx.doi.org/10.1590/ sajs.2014/20130342. doi: 10.1590/ sajs.2014/20130342

ELIAS, M. C. Manejo tecnológico da secagem e do armazenamento de grãos. Pelotas: Ed. Santa Cruz, 2008. 367p.

FACCION, C. E. Qualidade de sementes de feijão durante o beneficiamento e armazenamento. 49 f. Dissertação (Mestrado em Agronomia). Universidade Federal de Lavras,Lavras-MG, 2011.

FAO. Food and Agriculture Organization. (2014). Disponível em:<http://www.fao.org/faostat/en/\#data>.

FERREIRA, D. F. Sisvar: A computer statistical analysis system. Ciência e Agrotecnologia, v.35, p.1039-1042, 2011.

FERREIRA, F.A.; SILVA, A.A.; COBUCCI, C.; FERREIRA, L.R.; JAKELAITIS, A. Manejo de plantas daninhas. In: VIEIRA, C.; PAULA JR, T. Z. D.; BORÉM, A. (Org.) Feijão. Viçosa, MG: Universidade Federal de Viçosa, 2006. v. 2. p. 309-340.

FILHO, J. M. Fisiologia de sementes de plantas cultivadas. 1. ed., Piracicaba: Fealq, 2005. 495p. 
FRANÇA-NETO, J. B.; KRZYZANOWSKI, F. C.; HENNING, A. A. A importância do uso de sementes de soja de alta qualidade. Informativo ABRATES, v.20, p.037038, 2010.

HARTMANN, N.; ERBS, M.; WETTSTEIN, F. E.; HOERGER, C. C.; SCHWARZENBACH, R. P.; BUCHELI, T. D. Quantification of zearalenone in various solid agroenvironmental samples using D6-zearalenone as the internal standard. Journal of Agricultural and Food Chemistry, v. 56, n. 9, p. 2926-2932, 2008. Disponível em: <https://www.ncbi.nlm.nih.gov/pubmed/18412358>. doi:10.1021/jf8002448

HEIDTMANN-BEMVENUTI, R.; MENDES, G. L.; SCAGLIONI, P. T.; BADIALEFURLONG, E.; SOUZA-SOARES, L. A. Biochemistry and metabolism of mycotoxins: a review. African Journal of Food Science, v. 5, n. 16, p. 861-869, 2011.

Disponível

em:

<http://www.academicjournals.org/article/article1380101049_Heidtmann-

Bemvenuti.pdf>. doi: 10.5897/AJFSX11.009

ISTA, 2007. International Seed Testing Association - ISTA. International Rules for Seed Testing. Zurich:, 369p. Disponível em: <http://www.seedtest.org/en/home.html>.

KAPPES, C.; ARF, O.; FERREIRA, J. P.; PORTUGAL, J. R.; ALCALDE, A. M.; ARF, M. V.; VILELA, R. G. Qualidade fisiológica de sementes e crescimento de plântulas de feijoeiro, em função de aplicações de paraquat em pré-colheita. Pesquisa Agropecuária Tropical, v. 42, n. 1, p. 9-18, 2012. Disponível em: <http://www.scielo.br/pdf/pat/v42n1/02.pdf>.

KOLPIN, D. W.; SCHENZEL, J.; MEYER, M. T.; PHILLIPS, P. J.; HUBBARD, L. E.; SCOTT, T. M.; BUCHELI, T. D. Mycotoxins: diffuse and point source contributions of natural contaminants of emerging concern to streams. Science of the Total Environment, v. 470/471, p. 669-676, 2014. Disponível em: <https://ttp://dx.doi.org/10.1016/j.scitotenv.2013.09.062>. doi: 10.1016/j.scitotenv.2013.09.062

KRYYZANOWSKI, F. C.; VIEIRA, R. D.; FRANÇA-NETO, J. B. Vigor de sementes: conceitos e testes. 1. ed., Londrina: ABRATES, 1999.

LIMA, K. S. C.; SANTS, M.C.; PACHECO, S.; FREITAS-SILVA, O.; GODOY, R.L. O.; GODOY, R. L. O.; LIMA, A. L. S. Controle da micotoxina patulina por radiação gama e óleo essencial da noz moscada (Myristica fragrans). Semioses, v. 9, n. 1, p. 8-16, 2015. Disponível em: <http://dx.doi.org/10.15202/1981996X.2015v9n1p8>. doi: 10.15202/1981996X.2015v9n1p8

LOPES, M. M.; PRADO, M. O. D.; SADER, R.; BARBOSA, R. M. Efeitos dos danos mecânicos e fisiológicos na colheita e beneficiamento de sementes de soja. Bioscience Journal, v. 27, n. 2, p. 230-238, 2011. Disponível em: <http://www.seer.ufu.br/index.php/biosciencejournal/article/view/7123/7228>

MACHADO, J. C. Benefícios da Sanidade na Qualidade de Sementes. Informativo 
ABRATES, vol. 20, n.3, 2010.

MAPA, Ministério da Agricultura Pecuária e Abastecimento; Instrução normativa no 45, de 17 de 1 setembro de 2013. Disponível em: <http://www.agricultura.gov.br>.

MARTINS, A. B. N.; MARINI, P.; BANDEIRA, J. M.; VILLELA, F. A.; MORAES, D. M. Analysis of seed quality: a nonstop evolving activity. African Journal of Agricultural Research, v.9, n.49, p. 3549-3554, 2014. Disponível em: http://www.academicjournals.org/article/article1417523196_Martins\%20et\%20al.pdf> .doi: 10.5897/ AJAR2014.8912

MARTINEZ, H. E. P.; CLEMENTE, J. M.; LACERDA, J. S.; NEVES, Y. P.; PEDROSA, A. W. Nutrição mineral do cafeeiro e qualidade da bebida. Revista Ceres, v. 61(Suppl), p. 838-848, 2014. Disponível em: <http://dx.doi.org/10.1590/0034-737x201461000009>. doi:10.1590/0034737x201461000009

MICHELS, A. F.; SOUZA, C. A.; COELHO, C. M. M.; ZALIO. M. Qualidade fisiológica de sementes de feijão crioulo produzidas no oeste e planalto catarinense. Revista Ciência Agronômica, v. 45, n. 3, p. 620-632, 2014. Disponível em: <http://ccarevista.ufc.br/seer/index.php/ccarevista/article/view/2207/992>.

MOTA, D. H. Propriedades físicas durante a secagem e qualidade tecnológica em cultivares de feijão carioca em diferentes condições de armazenamento. 163 f. Dissertação (Mestrado em Agronomia), Faculdade de Agronomia e Medicina Veterinária, Universidade de Brasília, 2016.

MOTTA, T. P.; FRIZZARIN, A.; MARTINS, T.; MIRANDA, M. S.; ARCARO, J. R. P.; AMBRÓSIO, L. A; POZZI, C. R. Estudo sobre a ocorrência de fungos e aflatoxina B1 na dieta de bovinos leiteiros em São Paulo. Pesquisa Veterinária Brasileira, v. 35 , n. 1 , p. 23-28. 2015. Disponível em: <https://dx.doi.org/10.1590/S0100736X2015000100006>. doi:10.1590/S0100-736X2015000100006

NASCIMENTO, W. M. Tecnologia de sementes de hortaliças. 1. ed., Brasília: Embrapa hortaliças, 2009. 432 p.

PARREIRA, M. C.; LEMOS, L. B.; PORTUGAL, J.; ALVES, P. L. DA C. A. Effects of desiccation with glyphosate on two common bean cultivars: physiology and cooking quality of the harvested product. Australian Journal of Crop Science, v.9, n.10 p.925-930, $2015.2 \quad$ Disponível em:< http://www.cropj.com/parreira_9_10_2015_925_930.pdf>.

RIBEIRO, C.; TIRITAN, M. E. Development and validation of a gas chromatography mass spectrometry method for the analysis of phytoestrogens, phytosterols and mycotoxins in estuarine water samples. International Journal of Environmental Analytical Chemistry, v. 95, n. 3, p. 187-202, 2015. Disponível em: <http://dx.doi.org/10.1080/03067319.2014.1002492>.doi:10.1080/03067319.2014.10 02492

SANTOS, M. P.; VALE, L. S. R.; REGES, N. P. R.; CARVALHO, M. C. Desempenho 
de sementes de quatro cultivares de feijão (Phaseolus vulgaris L.) na microregião de Ceres - GO, Global Science Technology, v.08, n.03, p. 41-49, 2015. Disponível em: <http://rv.ifgoiano.edu.br/periodicos/index.php/gst/article/view/768/481>.

SILVA, F. H. A. Qualidade física, fisiológica e sanitária de sementes de feijãocaupi (Vigna unguiculata L. Walp.) utilizadas no Rio Grande do Norte. 2015. 85 f. Dissertação (Mestrado em Agricultura Tropical) - Universidade Federal Rural do Semi-Árido, Mossoró, 2015.

SILVA, M.; SOUZA, H. R. T.; DAVID, H. M. S. S.; SANTOS, L. M.; SILVA, R. F.; AMARO, H. T. R. Qualidade fisiológica e armazenamento de sementes de feijãocomum produzidas no norte de Minas Gerais. Revista Agro@mbiente On-Line, v.8, p.97-103, 2014. Disponível em: <http://dx.doi.org/10.18227/19828470ragro.v8i1.1346>. doi: 10.18227/1982-8470ragro.v8i1.1346

SOUZA, L. M. S.; SILVA, J. B.; GOMES, N. S. B. Qualidade sanitária e germinação de sementes de copaíba. Bioscience Journal, v.29, n.5, p. 1524-1531, 2013. Disponível em: <http://www.seer.ufu.br/index.php/biosciencejournal/article/view/15215/13298>.

ZUCARELI, C.; BRZEZINSKI, C. R.; ABATI, J.; WERNER, F.; RAMOS-JÚNIOR, E. U.; NAKAGAWA, J. Qualidade fisiológica de sementes de feijão carioca armazenadas em diferentes ambientes. Revista Brasileira de Engenharia Agrícola e Ambiental, v.19, n.8, p.803-809, 2015. Disponível em: <http://dx.doi.org/10.1590/1807-1929/agriambi.v19n8p803-809>. doi: 10.1590/18071929/agriambi.v19n8p803-809 